\title{
Histoid lesion in nerve of a lepromatous patient
}

\author{
A GIRDHAR, R K LAVANIA, G N MALAVIYA \& \\ B K GIRDHAR* \\ Central JALMA Institute for Leprosy, Tajganj, Agra, India
}

Accepted for publication 18 April 1990

Summary This report pertains to a patient who had untreated diffuse lepromatous disease of 8- to 10-years' duration. Two peripheral nerves were beaded, which on biopsy showed histoid features. Because of its rarity, the case is reported.

\section{Introduction}

Beaded thickening of nerves in lepromatous leprosy is not uncommon. However, histoid morphology in the nerve is a rarity, there being only few such recorded cases in the literature. ${ }^{1,2}$ Such a case is presented here.

\section{Case report}

RC, a 30-year-old male labourer from the western part of Rajasthan attended the outpatient department complaining of swelling all over the body of 8- to 10-years' duration. The condition started with paraesthesia in the distal parts of limbs, and thereafter insidiously progressed with diffuse infiltration all over the body. The patient was not aware of any patch or skin lesion at any time. He gave a history of frequent bloodstained nasal discharge. Apart from this he had no other problem and denied having taken any treatment whatsoever for his complaints.

On examination, he was found to have diffuse infiltration of the skin all over the body. It was more marked on the face, back, abdominal folds, buttocks, scrotum and the extensor aspects of the limbs. On the infiltrated skin of the left buttock, one pea-sized papule was present; otherwise there was no overt nodulation of the skin. He had thickening of the ears. In addition, there was loss of eyebrows on both sides. The tongue was infiltrated, the nasal mucosa ulcerated, and his hard palate showed nodulation. There was no evidence of ENL or of shrivelling of the skin anywhere. Both ulnars, superficial radials, and lateral popliteal nerves were moderately thickened, soft, smooth and

* Corresponding author. 


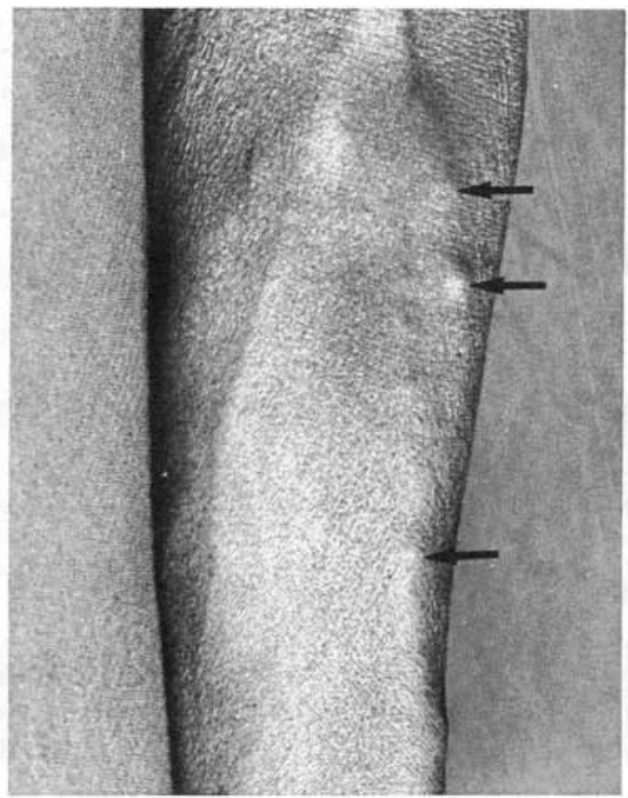

Figure 1. Nodules in the medial cutaneous nerve of the forearm.

nontender. The left medial cutaneous nerve of the forearm and the right superficial peroneal nerve were found to be grossly thickened, firm and beaded (Figure 1). There was glove and stocking distribution of pinprick analgesia on the limbs extending up to the middle of the legs but no paralytic or nonparalytic deformities. Systemic examination revealed no abnormality.

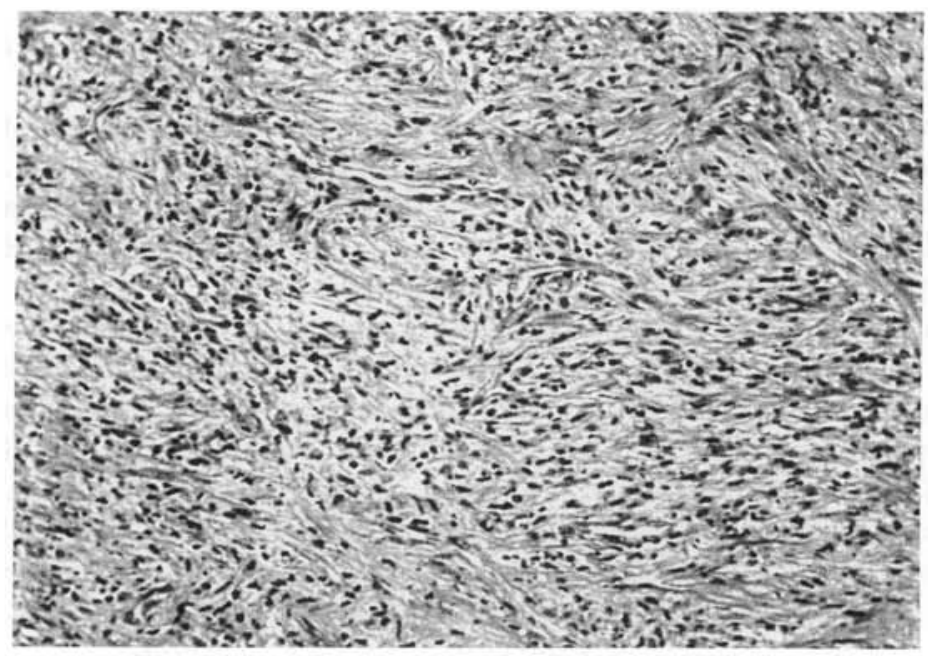

Figure 2. Interlacing strands of spindle shaped cells in the medial cutaneous nerve $(\mathrm{H} \& \mathrm{E} \times 10)$. 


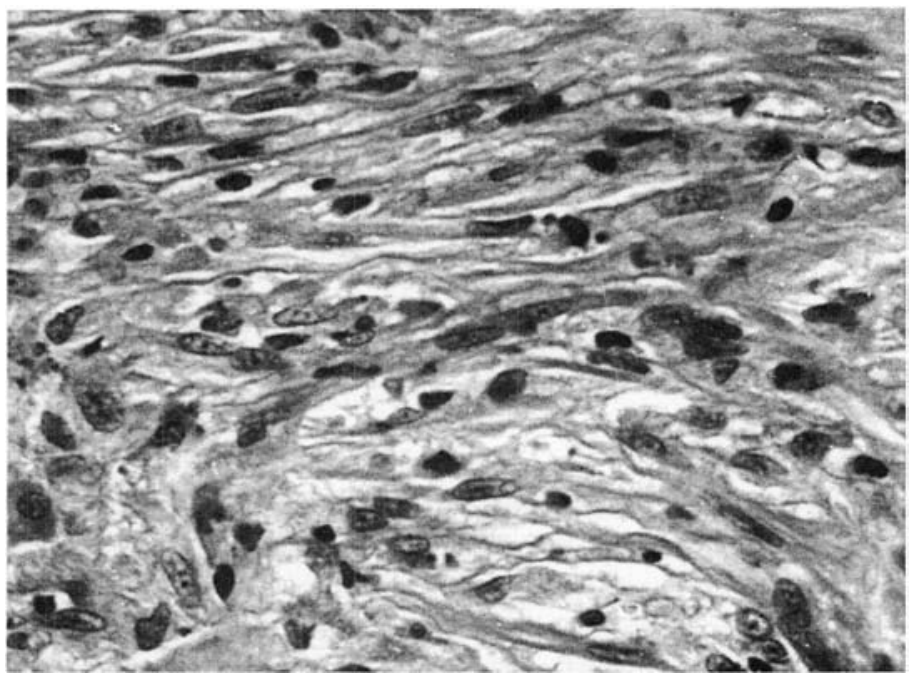

Figure 3. High power view of Figure 2 showing spindle shaped cells $(\mathrm{H} \& \mathrm{E} \times 40)$.

A clinical diagnosis of untreated lepromatous leprosy was made. A spot urine check for DDS was negative. Skin-smear examination showed that all sites were positive for acid-fast bacilli (AFB), the BI ranging from $4+$ to $5+$, mean $4.5+$. A nasal smear and the sputum too, were positive for AFB, the organisms being present in globi. Sputum culture for AFB was negative. A chest X-ray was normal. Liver function tests, blood urea and serum creatinine were found to be within normal limits.

Biopsy sections were processed, and stained with haematoxylin and eosin and Fite Faraco's stain for AFB. The Gless and Marsland technique was used for identifying nerve

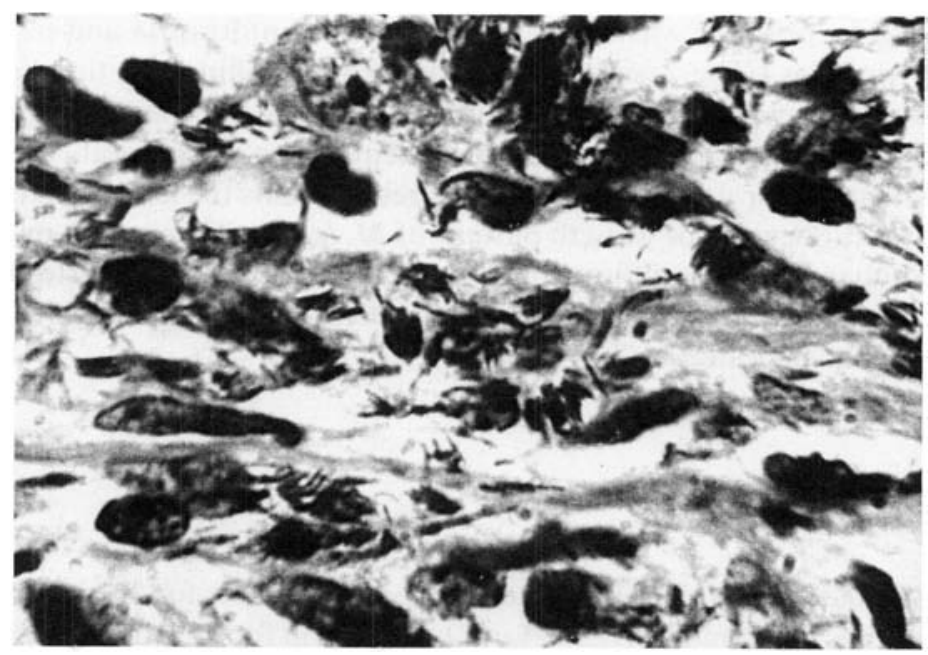

Figure 4. Spindle shaped cells packed with Mycobacterium leprae (Fite Fraco $\times 100)$. 
fibres. Skin from right flank showed a typically lepromatous picture with foamy macrophages loaded with AFB $(6+)$. The left medial cutaneous nerve of the forearm, which was beaded, showed nerve fibres and connective tissue infiltrated by spindle-shaped cells (Figure 2). In some areas there were interlacing strands of these spindle-shaped cells. Foamy macrophages were seen in other areas. Plasma cells and lymphocytes were seen scattered among the foamy macrophages (Figure 3). Solid-staining AFB were packed in the spindle-shaped cells (Figure 4) - a picture consistent with histoid leprosy in nerve.

\section{Discussion}

Since the original description of histoid leprosy by $\mathrm{Wade}^{3}$ the cutaneous and subcutaneous manifestations of histoid leproma have been well documented by several workers. ${ }^{4-8}$ While describing the histoid lesions in the skin of relapsed lepromatous patients, Wade ${ }^{3}$ suggested that the histoid lesions could occur in other situations as well. Indeed, soon afterwards it was found that several of the untreated lepromatous patients had histoid lesions on skin and possibly on palatal mucosa. ${ }^{5}$ In all the above studies, the histoid nodules were confined to the skin and/or mucous membrane and not elsewhere. More recently a few reports have appeared of histoid lesions occurring in nerves. Roy Chaudhari \& Srinivasan ${ }^{9}$ reported a 'histoid habitus' in a nerve abscess affecting the superficial radial nerve in an untreated nodular patient. Gaulier ${ }^{10}$ also reported a histoid morphology in the nerve of an untreated leprosy patient in whom large subcutaneous nodules were attached to the nerve trunk, or developing from it or its smaller branches. Ramanujam et al. ${ }^{1}$ and Rajan \& Palande ${ }^{2}$ have each reported typical histoid lesions in the nerves of relapsed leprosy cases.

Considering the frequency and extent of involvement of neural tissue in lepromatous patients, very few reports of neural histoids are available in literature. Further, all the previously reported cases of histoid leprosy were either relapsed patients with possibly resistant organisms, or if untreated they had nodular lepromatous disease. In contrast, the present lepromatous case was untreated, had diffuse infiltration and no cutaneous or subcutaneous nodules. The lesion was a fusiform swelling of the nerve. Histoid morphology was seen within the nerve bundles, the overlying sheath was normal.

The origin of histoid lesions in untreated patients, as in the present case and those of others ${ }^{9,10}$ remains unclear. It is likely that in all these patients the lesions in the nerves were due to altered multiplication or growth pattern of $M$. leprae. This in turn might result in a morphological change in the infiltrating cells. The possibility that histoid lesions may result from a localized and unchecked multiplication of $M$. leprae due to focal loss of immunity has been suggested by Job et al. ${ }^{11}$

\section{Acknowledgments}

The authors thank Dr K V Desikan and Dr C J G Chacko for having confirmed the histological findings independently, Sh Hari Om Agrawal for the photographic assistance and Sh S K Kulshrestha for secretarial help. 


\section{References}

1 Ramanujam K, Arunthathi S, Chacko CJG, Jacob M. Nerve histoid leproma in peripheral nerve; a case report. Le pr Rev, 1984; 55: 63-8.

2 Rajan MA, Palande DD. Histoid leprosy with histoid leproma in peripheral nerve - a case report. Lepr India, 1985; 57: 389-92.

3 Wade HW. The histoid variety of lepromatous leprosy. Int J Lepr, 1963; 31: 129-42.

${ }^{4}$ Price EW, Fitzherbert H. Histoid lepromatous leprosy. Int J Lepr, 1966; 34: 367-74.

5 Ramanujam K, Ramu, G. Wade's histoid lepromatous leprosy. Lepr India, 1969; 49: 293-7.

${ }^{6}$ Rodriguez JN. The histoid leproma-its characteristics and significance. Int J Lepr, 1969; 37: 1-21.

7 Desikan KV, Iyer CGS. Histoid variety of lepromatous leprosy. Int J Lepr, 1972; 40: 149-56.

${ }^{8}$ Bhutani LK, Bedi TR, Malhotra YK, Kandhari KC, Deo MG. Histoid leprosy in North India. Int J Lepr, 1974; 42: 174-81.

9 Roy Chaudhari SB, Srinivasan H. Nerve abscess in lepromatous leprosy. A case report and discussion of pathogenesis. Lepr India, 1977; 49: 330-8.

10 Gaulier A. Spindle shaped leproma cells arising from perineurium. A link with Wade's histoid leprosy, one case. Arch Anat Cytol Path, 1980; 28: 277-82 (In French) Abs Int J lepr, 1981; 49: 476.

11 Job CK, Chacko CJG, Taylor PM. Electronmicroscopic study of histoid leprosy with special reference to its histogenesis. Lepr India, 1977; 49: 467-70. 